\title{
The Great Ephemeral Tattooed Skin
}

Patricia MacCormack

Anglia Ruskin University

Submitted for publication in Body \& Society 2006

\begin{abstract}
:
The skin is always and already a series of planes which signify race, gender, age and such. Tattooing creates a new surface of potential significance upon the body. Tattooing can call into question concepts of volition in reference to the power to inscribe and define one's subjectivity through one's own skin, and the social defining of the subject. Skin is the involution or event between subject and object, will and cultural inscription, the social and the self. Feminism, particularly corporeal feminists, have attempted to think ways in which the female flesh may be recognized and self-defined without risking essentialism through reification of the meaning of 'woman's body'. Thinking the tattooed female body thus resonates with some of the risks and benefits feminism has found in theorizing a marginalized body. Using Deleuze, Guattari, Lyotard and other major influences on corporeal feminists this article explores ways in which significance is sought in skin and possible configurations of skin and world which challenge the desire to read the flesh as a legible incarnation of subjectivity.
\end{abstract}




\section{Keywords}

Skin, Tattoo, Subjectifiance, Signification, Affect

\section{The Great Ephemeral Tattooed Skin}

Tattoos create a new surface of the body as text. This surface has been represented, interpreted, designified and discursively exposed as an external articulation of some internal essence of the body upon which the tattoo is inscribed. This essay will attempt to rethink the tattooed body, tactically using the female tattooed body, as an example of the philosophical complexities of thinking a body's surface as a frontier between self and culture. Using Jean-Françoise Lyotard and Gilles Deleuze and Félix Guattari this article will posit the tattooed body as challenging both representations of the traditional female body and the body itself as an intelligible and spatially fixed phenomenon. The resonance between the tattooed body and the female body will be used in this essay. This tactic will assist in understanding the powers and possibilities of resistance involved in a subject's ability to signify their own body and the techniques by which a body is docile to culture's power to signify it. While the tattooed body as a site of analysis is minor compared to the female body as a historical site, the tattooed body is a body both invested with a sense of volitional signification of skin and a site of analysis by the non-tattooed body. Feminism's struggle toward volitional self-representation coupled with a justified suspicion at defining the body which risks essentialism, is reflected in the tattooed body as transgressive body demanding recognition but not necessarily one which seeks to reify the body once it is recognized. The tattooed body fails to signify 'normal' by its extensions and additions, seemingly contradicting connections with a female body defined in dominant phallocentric culture by lack. However both deviate from the unremarkable body as the material experience of human corporeality inextricable from the ways it is signified. Dominant discourse, however, is a problematic term subject to hegemonic rather than immobile systems of signification and representation, and so the tattooed body will be used as a starting point in thinking the ways in which non-dominant bodies can dissipate and distribute relations between significations of bodies rather than simply fail to signify within overarching structures. Finally, the body of the tattooed women in the West, as still a fairly remarkable phenomenon, will be explored to intensify the relationship between these two forms of corporeal signification.

Many theorists have engaged with the notion of tattooing as a mode of empowerment, yet these studies frequently posit their subjects as sociologically distant. The fissure between theorist/sociologist and tattooed subject often presents the tattooed subject as irreconcilable with her or his capacity to know the motivations for tattooing, searching for a meaning or purpose for tattooing and the motivations of the tattooed other. Yet tattooing itself is as complex as any other form of social creativity - in that motivation is not clear. The question could be turned from 'why does one tattoo one's body?' to 'why do we want to know why we or another tattoos'? Lyotard states 'To ask someone a question is to presuppose that the person understands it and wants to reply...do we ask this question about ourselves?... Or else they will not reply and the question will remain your business, and you'll have you deal with it without them.'(1991: 129) The results of these questions range from arguments that fail to sufficiently problematize the relationship between will and act, to studies that conflate the anthropological with the sociological (hence the term 'modern primitives'1) and forms of analysis, which remain ambiguous. However, like the female body, one does not need to replace the question with silence. What is at stake is what is invested in enquiry and how can the fissure between questioner and questioned, between bodies themselves, be thought differently? The desire to know becomes a desire to be affected, what Deleuze and Guattari call proximity rather than opposition. Proximity is a haecceity, a moment unique to time, place, event and intensities, not a repeatable project of analysis. 'This principle of proximity or appropriation is entirely particular and reintroduces no analogy whatsoever. It indicates as rigorously as possible a zone of proximity or copresence of a particle, the movement into which any particle is drawn...[an] appeal to an objective zone of indetermination or uncertainty, something shared or indiscernible.' (1987: 272-3) This essay will address the tattooed body as an altered corporeal plane and through the affects it evokes. The empowerment of being a tattooed body is not about choosing something taboo or transgressive to inscribe on the body in order to retaliate against strict regimes of signification. Tattooing is not necessarily a form of active will to present a body in relationship with the subject's own volition. The tattooed body problematizes binaries of the natural/volitional, surface/interior, discursive and designated. 


\section{The Signifying Skin}

Skin is the site of encounter between enfleshed self and society. The skin is where the self involutes into the world and the world into the self. Skin is a marked surface inscribed with texts of race, gender, sexuality, class, sanity or madness before it is marked by ink. These corporeal expressions exist beyond the choice of the individual to define them. They are inscriptions created by historical and social consensus, while tattoos are usually formed through individual or small peer group consensus. Where race and gender, problematic terms but socially stratified nonetheless, are comprehensible the tattoo can confound. Theoretically tattooing is available to most genders, races and cultures. The tattoo has signified liberation (through choice), commodification as fashion) and terrorization (in the Holocaust). It suggests individuality and belonging (subcultural, tribal, but also through the forced homogenization of tattooed people by non-tattooed culture). The surface the tattoo creates complicates the already complex sense of the immediacy between the internalisation of social discourse (from institutionalized discourse such as the prison to gendering) and the externalization of self enacting in the world. What philosophical questions can this body raise to deterritorialize the very notion of 'reading' a subject through the signifiers of the skin?

The division between the 'natural' materialization of skin and the cultural, volitional marking of skin by a tattooist's needle is perhaps best described as elucidating nuanced versus gross material expression rather than natural versus cultural skin. Either way skin is encountered as legible. Power could be seen as the interface between the discourses of society and self-expressed subjective inscription - from gender to race to body modification. The skin is where the self enters the world and the world enters the self, similar to Merleau-Ponty's model of two hands clasping each other. Even though the hands clasp, their relation is of two not of one, each with their own specificity, yet the two are indivisible. Elizabeth Grosz emphasizes the relation of power within this model. "For [MerleauPonty] there is always a slippage in the double sensation: they remain irreducible to each other. The left hand feeling the right hand is not the same as the right hand feeling the left.”(157) An individual's enactment of their body is different to society exerting power upon the body, but the inextricable nature of the encounter resonates with this phenomenological example. Each single body exerts forces upon its own sense of self, made from a selection of binary choices - male/female, black/white and etcetera coalesced into a unified subject. Deleuze and Guattari call this biunivocalization. Each body represents a constellation of forces, and assemblages of people can create strategic forces to alter the force of dominant culture. The specificity of a tattooed body is another layer of differentiation. Instead of an individual body having to privilege one aspect of difference over another - for example black women or lesbians having to deal with the politics of their race or sexuality separately from their gender $-\mathrm{a}$ body's differences create a specific plane of its own relationship to all its differences. Should a tattooed woman have to be a tattooed person when dealing with issues of body modification? Should she be a non-body modified woman when dealing with feminist issues? The skin of women as the interface of flesh within and as a part of culture is a contested site, as skin refers to everything from genetic sex to gender enactment, from real-life suffering to philosophical positioning. Skin itself marks the body as both taking up space and existing within a particular space. Within 'corporeal feminism' nothing can be thought without being thought materially, not because the body is now privileged over the mind but because it is impossible to refer to one without the other being included in any reference.

The expression Deleuze and Guattari use to refer to the illegible body is the 'Body without Organs' (BwO). The BwO is not a thorax emptied of its vital viscera but emptied of immobilized significations of the function, meaning and capacity for us to 'read' each aspect of corporeality reliably and permanently. The BwO is not a body without significations but any significations are localized, tactical and temporary. The BwO can refer to a space within a body, one body and a collective of persons (a political body). Most importantly the BwO exerts its forces not through its meaning but through its capacity to affect other forces and alter force relations. Affect is the openness and possibility of experiencing that irrevocably alters the self. Rather than reading a body's gender through the phantasmatically stable signifiers of skin, voice, genitals and face, the gendered tattooed body has potential(s) to affect(s). Instead of 'who is this (female, black, old) body?' one asks 'what is this body doing, to what is it connecting, what new formations is it creating?' Through expressing and confounding willful re-signification tattooed bodies thus become aware of their capacity to affect other bodies. Deleuze demarcates two axes of affect that elucidate all force expressed by all individuals, and the corresponding forms society's forces take as affect-relations. He states: 
To incite, provoke and produce (or any term drawn from an analogous list) constitute active affects, while to be incited or provoked, to be induced to produce, to have a 'useful' effect, constitute reactive affects. The latter are not simply the 'repercussion' or 'passive side' of the former but are rather 'the irreducible encounter' between the two, especially if we believe that the force affected has a certain capacity for resistance. At the same time, each force has the power to affect (others) and be affected (by others again) such that force implies power relations: and every field of forces distributes forces according to these relations and their variations. (Deleuze, 1988: 71)

The relation between macropolitical bodies, from 'phallocratic' dominant culture or feminism, to individual bodies in familial or localized situations, to a body's own potential to affect itself, any body's capacity to affect is what forms everyday 'real-life' encounters and their aptitude to repeat or transform power relations. The body is broken down (or broken up into larger assemblages) into segments or molecules of force that each express a capacity to affect. The organ-ized body, that is, the body whose meanings and functions are fixed, is read before it exists. However some who seek to 'know' risk coming to tattooed flesh with pre-established significations. An example of the tattooed person becoming an urban model for an anthropological study can be seen in Paul Sweetman's 'Anchoring the (Post-Modern) Self' in which he claims "Drawing...from interviews with a variety of contemporary body modifiers this section will suggest that for some tattooees and piercees, there is...evidence to suggest that their tattoos and piercings are experienced as more than mere accessories." (1999: 52) Even the title of the article points to the author's desire to anchor the meaning and potential of these bodies. His insistent inclusion, when citing his interviewees, of everyday banal speech (including 'erm...') juxtaposed against his theoretical language further positions the tattooed body as vaguely hierarchically inferior, a body to be analysed rather than a focus on the power relations and connections forged between tattooed and other bodies being acknowledged. We read the flesh into established modes of comprehension so that anything remarkable within a body is subsumed into a univocal series made from binary choices, which privilege one term over another's failure to signify the dominant. We see women as not men, racial others as not white. The tattooed body as not natural' or 'given' emphasizes the signifying regimes of materiality the discursive systems that precede it. Deleuze and Guattari state:

Let us consider the three strata that most directly bind us: the organism, signifiance, and subjectification. The surface of the organism, the angle of signifiance and interpretation, and the point of subjectification or subjection. You will be organized, you will be an organism, you will articulate your body - otherwise you're just depraved....To the strata as a whole, the $\mathrm{BwO}$ opposes disarticulation (or $n$ articulations) as the property of the plane of consistency, experimentation as the operation on that plane (no signifier, never interpret!), and nomadism as the movement (keep moving, even in place, never stop moving, motionless voyage, desubjectification). (1987:159)

The skin as the surface of the organism is interpreted through its signifiance - what an aspect means, and its subjectification - what signifiances assemble as in a unified single corporeal expression known as a subject. Signifiances and subjectification are phenomena of the flesh (inextricable from the psyche within it) but because they exist as and at the interface between experiencing the flesh of another and the self in the world they are both linguistic and corporeal. Signifiance and subjectification give the body a function, purpose and meaning in the world and give the world meaning, function and purpose to the body.

The axes of linguistic and corporeal emphasis and experience are where the organized body departs from the BwO. Instead of speaking my body or the body of another as it is, instead of living my body or seeing the body of another as being lived as a re-iteration of what that body is, the $\mathrm{BwO}$ speaks an open language of possibilities and corporeality as a creative involution of the body's relationship to the world. Interpretation is the body reflected in an already thought concept. To 'speak' the $\mathrm{BwO}$ would be to engage with what Foucault calls language that spreads forth rather than infers meaning. This nonsovereign mode of speech creates: "the void in which the contentless slimness of 'I speak' is manifested [is] an absolute opening thought which language endlessly spreads forth, while the subject the 'I' who speaks - fragments, disperses, scatters, disappearing in that naked space”(1987:11). To 'experience' the $\mathrm{BwO}$ resists all modes of comprehending 'it' in order to achieve 'it'. The $\mathrm{BwO}$ is what Rosi Braidotti would call the nomadic body. The BwO is continual transformation of the static body redistributed, intensity that presents in matter. 
A BwO is made in such a way that it can be occupied, populated only by intensities. Only intensities pass and circulate...It has nothing to do with phantasy, there is nothing to interpret. The BwO causes intensities to pass; it produces and distributes them in a spatium that is itself intensive, lacking extension. It is not a space nor is it in space; it is matter that occupies space to a given degree - to the degree corresponding to the intensities produced. (Deleuze and Guattari, 1987: 153)

Signification of subjectivity through skin is a persistent configuration of the mobile skin based on established patterns being repeated. To understand a body is to organize it. To organize a body is to exert a power over it, enclosing it in limited meaning. The body itself engages with and negotiates this power. The tattooed body resists organization by presenting another layer which must be organized, the signification of which is both volitional but neither clear nor stable. As a BwO it adds to the population of elements of skin, intensifies different points, and resist interpretation but also deterritorialize those planes of skin which precede it. Just as the signifier 'woman' is not a stable term beyond its failure to signify 'man', the tattooed body is the added-onto body that fails to signify the 'natural', 'raw' or 'unmarked' body, of course always and already marked with significations. An unfeminine woman or a rebellious woman who tattoo themselves to create their own visual or aesthetic representation may seem to resist traditional versions of femininity, but neither description gives the female body the volition of discursive self-representation. Deleuze and Guattari point to woman as already a BwO. They claim the un-organized bodies of children are invaded with organizing principles, the first being the principle of female lack, followed by the threat of male lack to organize the male.

The question is not, or not only, that of the organism, history, and subject of enunciation that oppose masculine to feminine in the great dualism machines. The question is fundamentally that of the body - the body they steal from us in order to fabricate opposable organisms. This body is first stolen from the girl: Stop behaving like that...The boy's turn comes next, but it is by using the girl as an example... the reconstruction of the body and a Body without Organs, the anorganism of the body, is inseperable from a becoming-woman. ${ }^{2}$ (Deleuze and Guattari, 1987: 276)

If the female body is thought as a $\mathrm{BwO}$ then where and what is tattooed upon it is at turns irrelevant, contingent in meaning, or a form of increasing the intensity of the BwO. Each description is a description of traditional women with tattoos, which alter their relationship to the traditional feminine. Deleuze states "We go from inflection to inclusion just as we move from the event of the thing to the predicate of the notion, or from 'seeing' to 'reading'.”(1993:41) Seeing a tattooed body is evocative but reading one envelops it into a comparative system of self and other, distancing its power to act as a catalyst toward thinking body relations differently. The interpretation exists before the tattooed body can. Whether the tattoo is seen as beautiful, political or tribal, 'reading' it stabilizes the meaning of a tattoo upon an organized body. If the body is resistant to being described as an organized body with a tattoo then the role and force of the tattoo in relation with the body can change the very definition of 'woman' that succeeds the adjective ‘tattooed'.

Like tattooed bodies in sociology, women's bodies in philosophy and psychoanalysis are more often spoken about than speak. Any discourse which does emerge is usually tempered by the difficulty of speaking a hitherto minimally acknowledged subject without reifying it. To re-present immobilizes the subject and evokes the intensely difficult conundrum of the need for a historically silent or silenced body to speak itself and the demand for such a body to speak risking essentialism. Can the body as a speaking subject remain mobile? It can if those bodies are addressed as sharing common histories of silence and being spoken about without their futures requiring their conflation as a unified group. The intensity of feminism as a $\mathrm{BwO}$ is an example of different bodies assembling to form a specific spatial and temporal force. Feminism describes a collective of very different people. For a variety of purposes these different people wish to resist the frequently homogenizing and repetitive force of dominant discourse. Here intensity corresponds to matter to the degree that forces from dominant systems can change the shape of this $\mathrm{BwO}$ and the $\mathrm{BwO}$ reacts in degrees to the spaces available to it (through need or opportunity) hence altering the matter of repeated patterns of dominant cultural ideology. We could call the non-dominant force 'feminism', even though it does not describe any single kind of person. The outcome will not necessarily be predictable, the intensity of the force of feminism will be based on the intensity of the resistance or give of dominant discourse and hence both forces will alter their shape and intensity dependent on how the relation of forces unfolds. There are no hard and fast rules to practices toward change, if there were many may be excluded instead of included in this BwO. For this reason feminism is not an organized body, it is a phenomenon produced through the intensities of the culture in which it exists and thus the direction, force and form of feminism's intensities are in constant 
circulation and flux. This is the power of feminism as a cultural need and a philosophy that includes the real-lived bodies of women. Women do not become immobilized as anything because the feminist movement itself is a $\mathrm{BwO}$. So if we can think the importance of feminism as a $\mathrm{BwO}$ what are the needs and risks of thinking women as such, and therefore tattooed women as an example of both a representation of women as the $\mathrm{BwO}$ and the $\mathrm{BwO}$ that is pure intensity without the signifiance of gender at all?

Tattooing has been referred to as a form of 'self-mutilation'. Women in particular have been the objects of analysis as representing the point at which body art and self-mutilation seem to lose their demarcation. Tattooing becomes another incarnation of self loathing, conflated with other corporeal pathologies such as anorexia, bulimia and 'self mutilation' (where all acts of opening the skin are themselves homogenized). Victoria Pitts cites Hesse-Biber, author of a text entitled Am I Thin Enough Yet? as claiming "Women particularly are pushing the envelope of body decoration and the question is why? - is this body enhancement or body dissatisfaction?” Pitts points out “The image Hesse-Biber depicts is instead presented as evidence for the suggestion that body-modifiers are victims...In this and other accounts the image of the suffering body-modifier is added to other figures of escalated female victimization, such as the anorectic, the 'delicate self harm' cutter and the objectified teenager”(297). Tattooed women can be represented as being tattooed because of body dissatisfaction, to attain a certain image as a result of social pressures to appear attractive. Simultaneously a tattooed woman is more likely to be represented as unfeminine, extreme or radically departing from the norms of feminization. Signification of the body before the tattoo is inked is important in contextualizing the image when the tattoo arrives. Psychoanalytically the body is first and foremost organized around the phallus, primarily the presence or absence of the phallus, and women come to be organized not so much on what their bodies signify but what they fail to signify. Race can be described similarly. The non-white body is not a specific and different body to the white body, it rather fails to signify whiteness. Hence the act of organizing bodies refers to the organization of a very particular kind of body, a white male body, and the failure or success of other bodies to fulfil the indices of this body. Here we find the female body defined in psychoanalytic terms as lacking.Renata Salecl, from within an adamently Lacanian frame, claims the disrespect for the body apparent in body art reflects disrespect for castration. She states "Respect is therefore an imaginary relationship that the subject has towards another subject, or, better, towards the symbolic status that this other subject temporarily assumes.(1998:34) Tattooed women are frequently described as disrespecting the sanctity of their female bodies, which Salecl could claim is a disrespect for the symbolic power of the phallus. Hence tattooed women and feminists are part of a greater frame of resistant women who must either continue to be defined through their antagonistic relationship with psychoanalysis and phallomorphism or think outside of lack.

Returning to the BwO the female tattooed body can redistribute the organized body. Although the following sentences are generalized I will refer to some gross stereotypes of tattooing momentarily to elucidate the importance of the body as organized, even if that body creates a new plane of interest by being tattooed. The organization of the body assists in 'interpreting' tattoos as much as tattoos themselves are able to signify. For example, certain parts of the female body are seen as 'appropriate' for tattoos, such as the hip, the upper thigh or the shoulder. These areas are often graced with 'feminine', small images. Being tattooed with large, less feminine images, blackwork (blocks of shapes flooded with black ink) or being tattooed in a place such as the arms, the neck, hands, mons verenis or face $^{3}$ are not generally described as feminine forms of tattooing. The male body is more a canvas able to be written on in its entirety, with the possible exception of the penis. It is interesting to note that the face and the penis are the rarest places one sees men tattooed. The significance of this will be discussed below.

Thinking female difference must then advocate thinking the flesh itself through a different system of corporeal (lack of) comprehension. Women have rightly refused lack as the defining point of their gender. If tattooing mutilates the female body, we should ask whose version of the female body is this body? Men do not get their penises tattooed on the whole because within a phallocentric system this is the symbolic signifier of their subjectification, the point where the flesh is already not marked but subsumed entirely as a symbol. Is the mutilation of a female body only a mutilation in one system of understanding the body? Can tattooing not only be non-mutilative in the $\mathrm{BwO}$ but a form of becoming the $\mathrm{BwO}$ ? Certainly if a man were to tattoo the penis heavily, replace its signifiance with new illegible symbols that changed the penis from a symbol of a phallus to something out of the ordinary, strange, or not acceptable, he would be on the way to becoming a BwO. ${ }^{4}$ Women are often tattooed in 'delicate' 
places, especially places where the tattoo can be easily hidden. The bikini-line, upper thigh or breast tattoo sometimes represents a secret gift for a lover, it is revealed when clothing is removed. Within phallocentric culture the revelation of a tattoo in these places, near the site of castration, could present as fetishes. This would explain the tattooed woman described as 'unfeminine', disavowing lack in a permanent way. If the images in these areas are 'feminine' - birds, butterflies etc - then this disavowal of castration is questioned. But how would psychoanalysis explain extreme tattooing such as large amorphous blackwork that does not represent an image but pure design, or animal print work where large parts of the body and head are covered in zebra stripes or leopard spots, scales or feathers? The whole body is territorialized by the becoming-animal of human skin or the redistribution of the body's traditional outline by large swirls and whorls of black. The body's 'look' as human is challenged. Issues of male or female tattooing are troubled by the introduction of human and non-human, and the distortion of body outline through the emergence of new abstract lines and forms. The body is organized now by the blackwork or the animal pattern, which may or may not cover the breasts and genitals, but reorganizes their role in bodily signification. The body is not white woman but zebraperson, not black man but barbershop spiral or a body being folded as blocks and shapes, repeated patterns that mean nothing.

\section{The Temporal Skin}

Félix Guattari calls the act of interpretation or 'knowing' a body the massacre of the body. He writes,

It is the body and all the desires it produces that we wish to liberate from 'foreign' domination. It is 'on that ground' that we wish to 'work' for the liberation of society. There is no boundary between the two elements. I oppress myself inasmuch as that I is the product of a system of oppression that extends to all aspects of living...We can no longer allow others to turn our mucous membranes, our skin, all our sensitive area into occupied territory - territory controlled and regimented by others, to which we are forbidden access. (1996a: 30-31)

Tattooing is one form of the many, micro-political acts a body can perform to re-occupy itself with multiple meanings. Tattooing should not be considered the form of dermic resistance par excellence simply because it is often described as permanent or extreme. It can be political or aesthetic or both, but it does include certain elements that disperse the traditionally organized body during and after the act of tattooing, transcendent of any particular reason for which the tattoo is acquired. Some of these elements include but are not limited to (and of course alter in their own expression between bodies and within the one body): pain; masochism; endurance; a sense of the capacity to alter the phantasmatically 'given' body; banality; economic or visual extravagance (tattoos cost a lot and look visually elaborate in many situations); a sense of permanence; continual transformation; narcissism; anacliticism (taking one's body as an object distinct from the self); extreme respect or disrespect of sense of self. This shopping list of motives and affects could continue infinitely even if I was to describe one body acquiring one tattoo. The point I am making, relating to Guattari's suggestion, is that for whatever reasons a body thinks or refuses to think the act of tattooing and being in a tattooed body, theorizing or interpreting such a body risks colonising the skin of one's self or another. If we judge what a tattoo 'means' we are holding it against an original and disavowing the specificity of any image, occupying the tattooed skin with transcendental essence. We bring a perceived 'natural' body massacre to an apparently synthetically placed rupture. If we ask the bearer (including ourselves) to articulate a tattoo's meaning we risk involuting the occupation so that even if (and it's a big if) the body expresses its own meaning, the body is forced to express within the dominant system's mode of intelligibility, given by s/he who asks the question. In occupation of the body meaning is given, not creatively forming new possibilities of meaning. Deleuze relates the project of definition thus:

A definition poses the identity of one term (the defined) with at least two other terms (definers or reasons). The definition can possibly be substituted for the defined, this substitution being the reciprocal inclusion: for example, I define 3 by 2 and 1...the definers or reasons must precede the defined since they determine its possibility, but only by following the 'power', and not the 'act' that, on the contrary, would suppose the antecedence of the defined. Whence, justly, reciprocal inclusion and the absence of all temporal relations. (1993:43)

The defined tattoo includes the reasons given by the definers or, if given by the tattooed as something outside the possibility of being defined within dominant discourse, comprehended (another way of saying defined) by the definers. In the situation of the tattooed woman we have two terms to be defined 
which produce a third. The act of tattooing is not taken as a dividuated phenomenon. The term 'woman' and the term 'tattoo' produce the term 'tattooed woman'. The third term is formed by the definition of the first two terms, which themselves are often formed by other multiple terms. Repeated patterns of discourse refer back to established possibilities of definition rather than new modes of embodiment. If terms do not go together within definitions they will sit uncomfortably and may incur discursive resistance. Traditionally terms like 'sailors', 'prisoners' or other gross stereotypes are congruent with 'tattoos'. The reasons for these have a (phantasmatic) historical clarity.

Dominant discourse demands motives for the partnership of woman and tattoos. Demanding a reason is a form of violence perpetrated upon the female tattooed body. The process of definition fixes the body, just as the process of prejudice that defines 'woman as...' has traditionally fixed the female body. If a definition is sought, if a reason is required, the body's capacity to become a $\mathrm{BwO}$ is re-occupied, subsumed. The act of tattooing may simply elucidate a rupture in the demand or compulsion for subjects to speak. The act of fixing refuses the body itself as temporal before it is tattooed, and may even perpetrate within traditional discourse the power of permanence because the risk of tattoos cited by both enthusiasts and critics is that tattoos are forever. Resistance in being a tattooed body may refer more to a resistance to define one's body than in the act of tattooing itself, a concrete example of Foucault's earlier call to 'speak' as an act that fragments, disperses, scatters, and makes meaning(s) disappear. Speech that fragments is like the tattooed body itself. Images, sounds and sensoria refer to possible futures and scattered micro sensations of the embodied psyche. The tattooed body as a $\mathrm{BwO}$ can be compared to the act of being tattooed. Contrary to popular apocraphy tattooing does not hurt because of 'the needle' (another object defined through its singularity both as object and in function $-a$ needle) but is more like a thousand tiny needles. "Leibniz is not saying that pain resembles an object, but that it evokes a vibration gathered by receptive organs: pain does not represent the needle, nor its movement from one level to another...but the thousands of minute movements or throbs that irradiate in the flesh...Pain does not represent the pin in extension, but resembles molecular movements that it produces in matter."(Deleuze, 1993:96-7) The experience of being a tattooed body or in proximity with a tattooed body does not represent the object of tattooed body or non-tattooed body next to tattooed body. These two phenomena evoke tiny perceptions of flesh experienced differently, sensorily, aesthetically, discursively. Both the body and the capacity to describe it scatter into thousands of fragmentary throbs, relational series and micro-corporeal and potentially political movements. The tattooed body is no longer addressed as an object but as an affective body that invites, through its similarity or difference to other bodies in proximity to it, a new experiencing of the body calling into question spatial permanence. Most tattooed people are no longer aware they are tattooed. Therefore the making aware of being a tattooed subject comes after a time mainly from the encounter with the discourse of other subjects - both tattooed and non-tattooed - thus being a tattooed subject is intensified based on the forces and affects of other bodies.

The permanence of tattooing comes into question when the meanings ascribed to an image are not fixed. Meaning must be mobile in order for the body to be thought as transformative. Images should not be occupied as representing a thing, but taken as durational phenomenon, like the rest of the body, renewed innumerably. How can we think the body temporally through an act that is most frequently described as a permanent marking of the skin? Even if we see the tattooed body as an affective body it is taken traditionally as a spatial phenomenon- i.e. the same body affecting other bodies, not a body able to affect and recreate itself. But Bergson states:

If it is a question of movement, all the intelligence retains is a series of positions: first one point reached, then another, then still another. But should something happen between these points, immediately the understanding intercalates new positions, and so on indefinitely. It refuses to consider transition; ... But it is always with immobilities, real or imagined, that it seeks to deal. Suppose we skip this intellectual representation of movement, which shows it as a series of positions. Let us go directly to movement and examine it without any interposed concept. (1992: 15)

The tattooed body thought as a body with additions to the prior body is a spatial body. Even extreme forms of all-over tattooing or certain non-signifying images, such as blackwork or animal skin work still remain definable as spatial if we choose to see them as, for example, a zebra-woman rather than a becoming-zebra. Tattoos are seen as either additions to the base level body or subtractions from the 'normal', passive or biological opposed to synthetic body. If the tattooed body is thought as a BwO it cannot be thought as ontological 'it'. 'What does this body mean?' refers to a spatial concept. 'What can this body do?' is an embodied philosophical, temporal question. Thus two major axes of thinking 
the tattooed body are thinking it affective-ly and durationally. Deleuze calls this the move from the object to the objectile. "The new status of the object" he states "no longer refers its condition to a spatial mold - in other words, to a relation of form-matter - but to a temporal modulation that implies as much the beginnings of a continuous variation of matter as a continuous development of form. ...[This] is not only a temporal but also a qualitative conception of the object, to the extent that sounds and colors are flexible and taken in modulation.”(1993:19) Thought materially tattooed bodies ripple, the skin modulates the image, which modulates the skin. The colors of tattoos change with light, with age, with the emotions of the viewer and the viewed. The tattoo is not necessarily an image of a thing, certain colors and lines can extricate themselves and be qualitatively affective, leaping from the skin or delving deeper into it as different colors react to different skin types.

\section{The Great Ephemeral Skin}

“Open the so-called body and spread out all its surfaces...” (Lyotard, 1993:1)

Lyotard states:

Spread out the immense membrane of the libidinal 'body' which is quite different to a frame. It is made from the most heterogeneous textures, bone, epithelium, sheet to write on, charged atmospheres, swords, glass cases, peoples, grasses, canvases to paint... The interminable band with variable geometry...has not got two sides, but only one, and therefore neither exterior nor interior. (1993: 2-3)

Jean-François Lyotard's embodied materiality resonates with Deleuze and Guattari's BwO. The body cannot help but be affected. It is, like the act of being tattooed, not the result of a meaningful choice to be affected but an accidental openness at the heart of being embodied that puts the body at the limits of a permanent quivering, what Deleuze would call, against the enunciation, a 'stutter', always and already occurring. This possibility is phylic, materially beyond the capacity to enclose it in 'reading' or 'interpretation', which is why reading must occur after an event, covering it over while preceding its potential. Inside and outside, tattooed and non-tattooed are materially inseparable, through differential relations between bodies, images, textures and smells, any sensory phenomena.

Tattooed bodies, like women's bodies, are often object rather than subject of analysis. Thinking the affective potential of the tattooed body flattens the surface of differential relation from object and subject to qualitative affect. Thinking tattooed flesh involves a flattening out and making connective the embodied mind so that the movement of being affected by this tattooed flesh creates a particular band, fold, plane of intensity. Corporeal and epistemological difference is not defined as difference from. Differences are both co-existent and specific intensities. Lyotard terms this band of differential relations the great ephemeral skin - ephemeral because it is immanently experienced (as opposed to transcendent or truthful), skin because, although not referring to 'a' body, the plane describes a corporeally embodied affective potential. Great for my purposes could suggest the area of skin in which Lyotard includes the flesh. This skin also includes (but does not oppose) image, thought, the viewed, the flesh of others and the opened body flattened out toward infinity. Looking at tattooed skin creates a band of surfaces of the retina with inked skin. In heat, tattoos (especially blackwork) raise, meaning tattoos can be experienced as purely tactile, offering the skin as a plane of embossed tactile band. We can think tattooing without seeing a tattoo and the affective potential of the suggestion (not concept) can modulate another involution of the band. Great is enormous in size, in shape, in possibility, in time, in matter, in dimensions, infinitely. The skin is not 'one's' skin, or 'my' skin, it does not seal, it folds, extends and opens. But my motive in this move to Lyotard is his focus on the figural rather than literal notion of skin. The meaning of skin itself as a plane of inclusion reconfigures the figural notion in phallocentric discourse of skin being the site of opposition. Tattooed skin provokes response, it invites other bodies to fold into it. It demands engagement whether the interlocutor is critical or celebratory of inked flesh. It silences the interlocutor as it folds because the tattooed body both emphasizes the problems in reading any body at any time, and fails to exist within an established epistemology. This is especially so of tattooed women who present (at least) two 'skin' epistemologies side by side - woman and tattooed body - both of which could be claimed as as-yet under or untheorized. "Meaning is never present in flesh and blood.”(Lyotard, 1993: 44) Like the tattoo meaning is inked into the flesh but the flesh resists it - like tattoos the meaning bleeds over time, the wearer will always have a different relationship to the images ascribed upon her/him. But culture's fascination with tattooed bodies (I could suggest, without conflating the two, comparable to culture's fascination with 
the female body) evinces the affective qualities elicited by being in proximity or within one of these bodies. They are rarely met with a lack of reaction.

Lyotard claims "To be side by side said the beautiful princess, is not to be alongside but to be inside and nevertheless indissociably in the margins.” (1993: 47) Tactically ignoring Lyotard's fetishisation of the feminine here, being alongside a tattooed body, even if it is one's own, twists one inside and politically alongside the margins of dominant culture. Far from subjugating the self, becomingmarginal questions the need for dominant culture to regulate the body. For those who wish to 'speak' the tattooed body the indissociability of that body with one's own body is always part of such speech. What is said about the body after the fact takes place perhaps despite, perhaps because of, the becoming of a great ephemeral skin of body(ies). Already by entering into a situation with a tattooed body, be it our own or that of others, embodiment itself has been renegotiated. Fascination with tattooed bodies is a form of desire - discursive, aesthetic, whatever - that will form new connexions of ephemeral skin irreversibly moving the flesh into different and differing folds and forces. "Little matter, but at least see what effects, not causes means," states Lyotard:

It is precisely not a matter of ana-lysing in a discourse that will be necessarily one of knowledge, but rather sufficiently refining ourselves, of becoming sufficiently anonymous conducting bodies, not in order to stop the effects, but to conduct them into new metamorphoses, in order to exhaust their metamorphic potential [puissance], the force [puissance] of effects that travel through us. (1993: 258)

Skin is the proximity of self and world. It is the point of intensity where everyday, unmeaningful pleasure happens, such as thermoception. It is also the surface upon which most forms of prejudice and terror are performed. Skin is where tattoos appear, but also where meaning is read, gender and race enacted. Skin goes right the way through the body, it is the surface of human morphology and the most minute gene. Organs have skin because they are signified, both symbolically and physiologically. Skin is the politic of flesh. Tattooing sits within the skin, as the skin sits within the frontier of culture and self. Neither extricate nor separate self from world, they are not borders but the point of inextricable assemblage or fold. Tattoos are not inscribed upon the surface but penetrate beneath our capacity to wrench them out, physically and epistemologically. In this essay I have attempted to show both that tattooing is a radicalizing of the skin, and the skin itself is a point where philosophy and our relationship with the world can be radicalized, in reference to difference, especially gender. Tattooing incites, provokes, hopefully in a way that further multiplies differences between bodies. If this is so, then the subjectification of bodies to a homogenous system of comprehension can be resisted by bodies that find joy in inscribing difference. Despite claims that tattoos are themselves increasingly homogenizing in both a consumer fashion and tribal sense the amount of resistance 'conservative' culture meets them with evinces their continuing potential to alter power relations. Optimistically I would suggest that because traditional forces are reactive to the affect of tattooing, tattooing represents a form of active force. This activity comes from the body's reaction to cultural restrictions in reference to what a body can mean before it restricts what a body can do. Tattooing is an experiment in being a body amongst other bodies. It playfully addresses issues of inside and outside, self and other, and volition and passivity that are ambiguous in all bodies by further complicating the body with sometimes legible and sometimes illegible forms. Tattoos both invite and resist the gaze of others. Tattooed bodies are often antagonistic to being stared at because of the fissure the onlooker is affirming through their fetishization or distaste at the tattooing. But looking in fascination as an opening up to being affected transforms looking and knowing to seeing and thinking. Deleuze states: "Seeing is thinking and speaking is thinking, but thinking occurs in the interstice, or the disjunction, between seeing and speaking.” (1988:87, my emphases) Tattooing at best makes us think the flesh differently, which has positive effects for thinking historically subjugated essentialized flesh, such as that of women. We see tattoos on the skin just as we see gender on the skin, and both are infinitely complex in their capacity to make us speak our own bodies and their force in the world. Tattooing and skin itself occur in an equivalent interstice, forming and forcing the disjunction between matter and thought, inside and outside, self and other and philosophy and affect. Tattooing is both an expression of will and a failure of a will to be self-evident. One's own relationship to one's tattoos is as complex as the relationship of the non-tattooed to tattooing. Tattooing's capacity to make philosophy readdress issues of bodies as intensity and momentum is where its real power lies. Deleuze and Guattari claim "Paintings, tattoos, or marks on the skin embrace the multidimensionality of bodies."(1987: 176) Open thought about the affect of bodies that scatters and fragments, Foucault's call to speech, embraces the multidimensionality of those bodies that allow us to rethink bodies themselves. The power of any BwO 
is not in what it is or prescriptive modes of achieving it, but in how we can think the body differently by entering it into new relations, forces and folds through flesh and thought. 


\begin{abstract}
Notes
${ }^{1}$ There is a tension between the modern primitive that engages in practices considered primitive (such as piercing, scarification and tattooing) and self-proclaimed modern primitives who claim to be representing a former, 'less civilised' mode of corporeal transformation toward a spiritual goal, such as Fakir Mustafa. Both attempt to subvert the negative connotations implicit in the word 'primitive'. Yet those who use the body to create and subvert traditional experience and those who are re-creating a form of tribal experience are radically different and discursively phylic in practices and motivation (or a lack of a claim to motivation).

${ }^{2}$ The problematic notion of becoming-woman as a simultaneous fetishisation and ablation of the particularities of women's suffering and minority positioning has been addressed extensively. Time does not permit me to explore it here.

${ }^{3}$ The face is a place seemingly inappropriate for both sexes because the face, according to Deleuze and Guattari, is the plane of signifiance and subjectification par excellence. The face more than any other surface, with the possible exception of the genitals, is the legible tableau of the subject's being. Because the genitals are not seen in everyday life the face becomes a semi-sacred site of selfrepresentation. Tattooing the face becomes taboo and many tattooists will not tattoo faces, especially the faces of women. Andrea Juno's interview with full body tattooed Michael Wilson includes the question “After you got your face tattooed did the world change?” (In Juno and Vale, 1989, 39) Writer and artist Jane Handel is the only woman in the Modern Primitives book with facial tattooing - small tears and dots under her eyes. Even through the fashion zenith of female tattooing in the early 1990s the facial tattoo was a rare sight.

${ }^{4}$ This is seen in such artists as Bob Flanagan and particularly Australian performance artists Pluto. See Patricia MacCormack’s ‘Facial Futures and Probe Heads: From Australia Post to Pluto' Journal of Australian Studies, 81: 135-143. 2004.
\end{abstract}

\title{
References:
}

Bergson, Henri (1992) The Creative Mind: An Introduction to Metaphysics Trans Mabelle L. Anderson. New York: Citadel.

Braidotti, Rosi (1994) Nomadic Subjects: Embodiment and Sexual Difference in Contemporary Feminist Theory New York : Columbia University Press.

Deleuze, Gilles (1988) Foucault Trans. Seán Hand. Minnesota: University of Minneapolis Press.

Deleuze, Gilles (1993) The Fold: Leibniz and the Baroque Trans. Tom Conley. Minnesota: University of Minneapolis Press.

Deleuze, Gilles and Guattari, Félix (1987) A Thousand Plateaus: Capitalism and Schizophrenia Trans. Brian Massumi. Minnesota: University of Minneapolis Press.

Foucault, Michel (1977) Discipline and Punish: The Birth of the Prison Trans. Alan Sheridan. London: Penguin.

Foucault, Michel (1987) 'Maurice Blanchot: The Thought from Outside' Trans. Brian Massumi Foucault/Blanchot New York: Zone Books.

Guattari, Félix (1996a) 'In Order to End the Massacre of the Body’. Trans. Jarrod Becker. In Guattari, Félix Soft Subversions Edited by Sylvére Lotringer. New York: Semiotext(e): 29-36.

Grosz, Elizabeth (1999) 'Merleau-Ponty and Irigaray in the Flesh' In Dorothea Olkowski and James Morley. (eds) Merleau-Ponty, Interiority and Exteriority, Psychic Life and the World. Albany: SUNY. 
Irigaray, Luce (1985) Speculum of the Other Woman Trans. Gillian Gill. Ithaca and New York: Cornell University Press

Juno, Andrea and Vale, V. (1989) Modern Primitives: An Investigation of Contemporary Adornment and Ritual San Francisco: V/Search

Lyotard, Jean-Francois (1991) The Inhuman Trans. Geoffrey Bennington and Rachel Bowlby. Stanford: Stanford University Press

Lyotard, Jean-Francois (1993) Libidinal Economy Trans. Iain Hamilton-Grant. Indianapolis: Indiana University Press

Pitts, Victoria (1999) 'Body Modification, Self-Mutilation and Agency in Media Accounts of a Subculture,' Body and Society 5 (2-3): 291-303

Salecl, Renata (1998) 'Cut in the Body: From Clitoridectomy to Body Art'. New Formations Special Issue on the Ethics of Violence, 35 (Autumn): 28-42

Sweetman, Paul (1999) ‘Anchoring the (Post-Modern) Self,' Body and Society 5 (2-3):51-76. 